transit time has previously been shown, ${ }^{5}$ phototherapy-induced lactose intolerance being implicated as a cause. ${ }^{6}$

We thank Miss $M$ White of the Haematology Department, St Luke's Hospital, Bradford, for use of the spectrophotometer, and Mrs J Doyle for typographical assistance.

\section{References}

1 Gibson J P. Reaction of 150 infants to cold formulas. $J$ Pediatr 1958; 52 : 404-6.

2 Davidson M. Gastrointestinal tract. In: Rudolph A M, ed. Pediatrics. New York: Appleton-Century-Crofts, 1977; 977-1062.

3 Preis O, Rudolph N. Abdominal distension in newborn infants on phototherapy-the role of eye occlusion. $J$ Pediatr 1979; 94: 816-9.

4 Husband J, Husband P. Gastric emptying of water and glucose solutions in the newborn. Lancet 1969; ii: 409-11.

5 Rubaltelli F F, Largajolli G. Effect of light exposure on gut transit time in jaundiced newborns. Acta Paediatr Scand 1973; 62: 146-8.

- Bakken A F. Temporary intestinal lactase deficiency in light treated jaundiced infants. Acta Paediatr Scand 1977; 66: 91-6.

Correspondence to $\mathrm{Dr}$ I Blumenthal, Department of Paediatrics, St James's Hospital, Leeds LS9 7TF.

\title{
Management of leukaemic infiltration of the testis
}

\author{
A OAKHILL, D MAINWARING, F G H HILL, P GORNALL, R E CUDMORE, \\ A J BANKS, J E S BROCK, J MARTIN, AND J R MANN
}

\author{
Children's Hospital, Birmingham, and Alder Hey Hospital, Liverpool
}

SUMMARY Of 95 boys treated for acute lymphoblastic leukaemia 25 have developed leukaemic infiltration of the testes. In 15 children relapse was apparently confined to the testes, and since treatment 7 of these boys remain in remission. The median duration of remission after testicular relapse was 72 weeks, considerably longer than that reported after other forms of leukaemic relapse.

Now that long haematological remissions occur in children with acute lymphoblastic leukaemia (ALL) greater attention is being paid to extramedullary sites of leukaemic relapse. Prophylactic therapy to the central nervous system has reduced the incidence of meningeal leukaemia, but in boys residual disease in the testis now presents an important obstacle. ${ }^{1}$

The management and prognosis of boys with leukaemic infiltration of the testis may depend on whether the relapse is confined to the testis or associated with previous or concurrent relapse elsewhere. We report our experience with 'isolated' testicular relapse.

\section{Patients and treatment}

Between December 1970 and June 1976, 95 boys were treated for ALL at our two centres, and leukaemic infiltration of the testis was detected in 25 of them.

$15(17 \%)$ had no evidence of leukaemia elsewhere and had had no previous relapses, so the disease was apparently confined to the testes. All had been treated according to current Medical Research Council UKALL I-V protocols, and 13 of them had features at diagnosis that suggested good prognoses. Two boys, one with a white cell count $>20 \times 10^{9} / 1$ and one aged over 14 years, were thought to have a poorer outlook (Table). In 13, testicular relapse (TR) was suspected clinically while in 2 it was discovered by routine testicular biopsy at the end of 2 years' treatment. The diagnosis was confirmed by needle biopsy in 9 patients and by wedge biopsy in 6 . Testicular disease was diagnosed during 'maintenance' chemotherapy in 3 , and between 1 and 24 (mean 7.8) months after stopping treatment in the remaining 12 boys. Both testes were affected in 9 boys and 6 had only unilateral infiltration.

Since 1975, we have used a standard treatment for isolated TR consisting of irradiation to both gonads and cords to a total tumour dose of $2500 \mathrm{rad}$ (given in 10 fractions), and 2 years' intensive chemotherapy usually with the UKALL II 'maintenance' protocol. ${ }^{2}$ Three early cases had lower doses of radiotherapy (Case 4 had 1800 rad in 6 fractions, Cases 10 and 11 $1500 \mathrm{rad}$ in 5 fractions). No further prophylaxis to the central nervous system was given.

The 10 children with previous or concurrent haematological or meningeal relapse were individually treated and all died of leukaemia (median survival 38 weeks); they will not be described further.

Treatment results. All 15 boys with isolated TR showed a clinical response to treatment but 5 suffered 
Table Data for 15 boys with leukaemic infiltration of the testes

\begin{tabular}{|c|c|c|c|c|c|c|}
\hline Case & $\begin{array}{l}\text { Prognostic } \\
\text { features at } \\
\text { presentation }\end{array}$ & Extent of $T R$ & $\begin{array}{l}\text { Age when TR } \\
\text { diagnosed (years) }\end{array}$ & $\begin{array}{l}\text { Time from } \\
\text { presentation until } \\
\text { TR (weeks) }\end{array}$ & $\begin{array}{l}\text { Time off } \\
\text { treatment before } \\
\text { TR (weeks) }\end{array}$ & $\begin{array}{l}\text { Remission length } \\
\text { since TR (weeks) }\end{array}$ \\
\hline 1 & Good & Bilateral & 8 & 134 & 21 & $24 \dagger$ \\
\hline 2 & Good & Bilateral & 6 & 122 & 12 & $71 t$ \\
\hline 3 & Good & Bilateral & 5 & 140 & OT & $60 t$ \\
\hline 4 & Good & Bilateral & 10 & 180 & 12 & $>236$ \\
\hline 5 & Good & Bilateral & 5 & 150 & 32 & 132 \\
\hline 6 & Good & Bilateral & 9 & 150 & 26 & $>144$ \\
\hline 7 & Good & Bilateral & 7 & 116 & OT & 54 \\
\hline 8 & Good & Bilateral & 14 & 104 & OT & 32 \\
\hline 9 & Poor & Bilateral & 5 & 134 & 9 & $72 \dagger$ \\
\hline 10 & Poor & Unilateral & 6 & 152 & 40 & $>147$ \\
\hline 11 & Good & Unilateral & 12 & 129 & 20 & $>100$ \\
\hline 12 & Good & Unilateral & 11 & 148 & 36 & $>91$ \\
\hline 13 & Good & Unilateral & 4 & 121 & 4 & 44 \\
\hline 14 & Good & Unilateral & 9 & 213 & 96 & $>30$ \\
\hline 15 & Good & Unilateral & 6 & 73 & 18 & $>58$ \\
\hline
\end{tabular}

OT $=$ on treatment, $\mathbf{T R}=$ testicular relapse.

+ Dead.

*Defined to have poor prognosis if one of the following features is present: WCC $>20 \times 10^{9} / 1$, aged $>13$ years, mediastinal mass, doubtful cytology, Negro race.

subsequent haematological relapse between 24 and 132 weeks later, 2 boys had meningeal relapse after 44 and 72 weeks, and one died of subacute sclerosing panencephalitis after 60 weeks.

On 1 May 1979, 7 boys were alive and well without further relapse between 30 and 236 weeks after diagnosis of TR. Four children had died, while the remaining 4 were alive but still receiving treatment for haematological or meningeal relapse, or both (Table). The median duration of remission after treatment of TR was 72 weeks.

Needle biopsy of the testes was repeated in Cases 7 and 8 (Table) 52 weeks after testicular irradiation and no leukaemic infiltration was found, although interstitial fibrosis and loss of tubular epithelium were present.

Two boys (Cases 4 and 8) have shown normal pubertal development after testicular irradiation. Two others (Cases 11 and 12) are currently undergoing pubertal changes.

\section{Discussion}

Leukaemic infiltration of the testis is more often being recognised in boys treated for ALL, perhaps because haematological remissions are becoming longer. The incidence of TR has been reported to be between 8 and $16 \%{ }^{3-5}$ However, Eden et al. ${ }^{1}$ found that $30 \%$ of boys entered into the Medical Research Council's UKALL trials I to III had developed this complication, not surprisingly a figure close to ours (26\%). The incidence of apparently isolated TR was $17 \%$ in our patients and $13 \%$ in the MRC series.

The prognosis for boys with TR who have had previous or concurrent haematological relapse is poor, 19 of 20 boys having had short further remissions, or none. ${ }^{6}$ These results resemble those for treatment of haematological relapse; Cornbleet and Chessells ${ }^{7}$ found median second remission lengths after haematological relapse to be 12 weeks for patients relapsing during treatment and 35 weeks for those relapsing after treatment had ended.

The outlook for boys with isolated TR may be better, particularly if this is diagnosed early and treated adequately with radiotherapy and intensive chemotherapy. In Memphis ${ }^{6} 1100$ to $2400 \mathrm{rad}$ to one or both gonads, and chemotherapy, produced long remissions (37-138 months) in 4 of 5 boys with isolated TR, while, after treating 111 boys with TR (7 of 47 with isolated TR survived) Schaison et al. ${ }^{5}$ recommended 2400 rad to both gonads, and further chemotherapy for isolated TR. Atkinson et al. ${ }^{8}$ also recommended 2400 rad to sites of extramedullary leukaemia; this was the dose we used, together with further chemotherapy, for our patients. This treatment had eradicated lymphoblasts from the testes of our 2 boys who had further biopsies 52 weeks after radiotherapy, but it produced the expected damage to spermatogenesis. Thus, boys surviving after this treatment will be infertile, but Leydig cell function appears to be adequate, at least for some years, to permit normal sexual maturation.

The median remission length for our boys treated for isolated TR was 72 weeks, and 7 of our 15 patients are still apparently in complete remission $\mathbf{3 0}$ to 236 weeks after diagnosis of TR. This period of follow-up is shorter than for the Memphis series and further relapses are still possible. However, as in the French series, ${ }^{5}$ the median remission length of 72 weeks after isolated TR greatly exceeded that reported after haematological relapse, ${ }^{79}$ so it is possible that radiotherapy and chemotherapy, as 
used for our patients, may cure some boys. Diagnosis of residual disease in the testis by routine biopsy before completion of chemotherapy may permit detection of those boys who require this treatment and perhaps improve the overall outlook for boys with leukaemia.

We thank Dr A H Cameron and Dr J M Bouton for their help and advice in the management of these patients, and the paediatricians who referred them to us for treatment.

A $\mathrm{O}$ was in receipt of a Leukaemia Research Fund Oncology Training Fellowship.

\section{References}

1 Eden O B, Hardisty R M, Innes E M, Kay H E M, Peto J. Testicular disease in acute lymphoblastic leukaemia in childhood. Br Med J 1978; i : 334-8.

2 Hardisty R M, Kay H E M, Peto J. Effects of varying radiation schedule, cyclophosphamide treatment, and duration of treatment in acute lymphoblastic leukaemia.
Report to the Medical Research Council by the Working Party on Leukaemia in Childhood. Br Med J 1978; iii: 787-91.

3 Stoffel T J, Nesbit M E, Levitt S M. Extra medullary involvement of the testes in childhood leukemia. Cancer 1975 ; 35: 1203-11.

4 Kuo T T, Tschang T P, Chu J Y. Testicular relapse in childhood acute lymphocytic leukemia during bone marrow remission. Cancer 1976; 38: 2604-12.

5 Schaison G, Jacquillat Cl, Weil M, Auclerc M-F, Desprez Curely J-P, Bernard J. Reclucte à localisations gonadique au cours des leucémies aignës 113 cas. Nouv Presse Med 1977; 6: 1029-32.

6 Hustu H P, Aur R J A. Extramedullary leukaemia. Clin Haematol 1978; 7: 325-34.

7 Cornbleet M A, Chessells J M. Bone marrow relapse in acute lymphoblastic leukaemia in childhood. Br Med J 1978; ii: 104-6.

8 Atkinson K, Thomas P R M, Peckham M J, McElwain T J. Radiosensitivity of the acute leukaemic infiltrate. Eur J Cancer 1976; 12: 535-40.

9 Kearney P J, Baumer J H. Letter: Relapse in acute lymphoblastic leukaemia. Br Med J 1978; ii : 639-40.

Correspondence to Dr A Oakhill, Children's Hospital, Ladywood Middleway, Ladywood, Birmingham B16 8ET.

\title{
Decreased serum tuftsin concentrations in sickle cell disease
}

\author{
ZVI SPIRER, YOSEF WEISMAN, VERA ZAKUTH, MATI FRIDKIN, AND NAHUM BOGAIR \\ Division of Paediatrics, Governmental Municipal Medical Centre, Tel Aviv University Medical School, and \\ Department of Organic Chemistry, The Weizmann Institute of Science, Rehovot, Israel
}

SUMMARY The serum concentrations of the phagocytosis-stimulating peptide, tuftsin, were determined by radioimmunoassay in 21 patients with sickle cell disease and in 12 healthy controls. The mean serum tuftsin concentration was significantly lower in patients with haemoglobin SS disease $(154 \cdot 3 \pm 35 \cdot 1$ $\mathrm{ng} / \mathrm{ml} ; 308.6 \pm 70.2 \mathrm{nmol} / \mathrm{l}, \mathrm{P}<0.01)$ and in patients with haemoglobin SC and CC disease $(180 \cdot 9 \pm 42 \cdot 7 \mathrm{ng} / \mathrm{ml} ; 361 \cdot 8 \pm 85 \cdot 4 \mathrm{nmol} / 1$, $\mathrm{P}<0.05)$ than in healthy controls $(228.7 \pm 46 \cdot 7$ $\mathrm{ng} / \mathrm{ml} ; 457 \cdot 4 \pm 93 \cdot 4 \mathrm{nmol} / \mathrm{l})$. Tuftsin deficiency is an indicator of splenic hypofunction and may contribute to the increased susceptibility of patients with sickle cell disease to severe infection.

Najjar and his associates described a cytophylic gammaglobulin, leucokinin, that stimulates phagocytosis by polymorphonuclear leucocytes and macrophages. The full biological activity of leucokinin resides in a tetrapeptide (Thr-Lys-Pro-Arg) named tuftsin, which is covalently bound to the heavy chain of the gammaglobulin. ${ }^{1-2}$ It is believed that the spleen is actively involved in either the generation or the release, or both, of the peptide from its carrier heavy chain as serum tuftsin concentrations are very low after elective splenectomy, and in functional asplenia due to infiltrative disease or infarction of that organ..$^{3-5}$ Functional asplenia contributes to the increased susceptibility of patients with sickle cell disease (SCD) to severe infections. ${ }^{6}$ We have, therefore measured the serum tuftsin concentrations in patients with SCD and compared the values with those found in healthy controls.

\section{Patients and methods}

21 patients (14 with homozygous SS disease, 5 with haemoglobin SS disease, and 2 with haemoglobin CC disease) and 12 healthy age-matched controls were studied; the patients and controls were aged between 3 and 21 years. The patients were neither infected nor in crisis at the time or during the 6-month period preceding blood collection, and none of them had been transfused in the 6 months before the study. In 7 of the patients with haemoglobin SS disease, 